\title{
CONSTITUTIVE MODELING AND NUMERICAL SIMULATION OF FRP CONFINED CONCRETE SPECIMENS
}

\author{
Gopinath SMITHA ${ }^{1 *}$, Avadhanam RAMACHANDRAMURTHY ${ }^{1}$, Ranganatha Iyer NAGESH ${ }^{1}$, \\ Eduvammal Kunhimoideen SHAHULHAMEED ${ }^{1}$
}

\begin{abstract}
Fiber-reinforced polymer (FRP) composites are generally used for the seismic retrofit of concrete members to enhance their strength and ductility. In the present work, the confining effect of Carbon Fiber-Reinforced Polymer (CFRP) composite layers has been investigated by numerical simulation. The numerical simulation has been carried out using nonlinear finite element analysis (FEA) to predict the response behaviour of CFRP-wrapped concrete cylinders. The nonlinear behaviour of concrete in compression and the linear elastic behaviour of CFRP has been modeled using an appropriate constitutive relationship. A cohesive model has been developed for modeling the interface between the concrete and CFRP. The interaction and damage failure criteria between the concrete to the cohesive element and the cohesive element to the CFRP has also been accounted for in the modeling. The response behaviour of the wrapped concrete specimen has been compared with the proposed interface model and with a perfectly bonded condition. The results obtained from the present study showed good agreement with the experimental load-displacement response and the failure pattern in the literature. Further, a sensitivity analysis has been carried out to study the effect of the number of layers of CFRP on the concrete specimens. It has been observed that wrapping with two layers was found to be the optimum, beyond which the response becomes flexible but with a higher load-carrying capacity.
\end{abstract}

Address

1 CSIR - Structural Engineering Research Centre, CSIR Campus, Taramani, Chennai-600113, India

Corresponding author: smithag@serc.res.in

\section{INTRODUCTION}

Demand for seismic strengthening has increased due to a better understanding of seismic risk and also because of the revision of existing codes. There has been a worldwide acceptance in the use of composite materials for the rehabilitation of deficient reinforced concrete (RC) structures. One important application of this composite retrofitting technology is the use of FRP jackets to provide an external confinement of structural elements when the existing capacity of the structure is inadequate. Each structural component has a specific function to perform, and confinement has proven to be very effective in increasing the strength of concrete and the ductility of members primarily subjected to compression. $\mathrm{RC}$ columns need to be laterally confined in order to prevent large deformations under loads before failure and to provide an adequate load resistance capacity. In the case of a seismic event, energy dissipation provided by a well-confined concrete core can often save lives. On the contrary, a poorly confined concrete column behaves in a brittle manner, leading to sudden and catastrophic failures. 
The axial behavior of CFRP-confined concrete has been extensively studied by researchers (Toutanji, 1999; Xiao and Wu, 2000; Campione, 2006; Colomba, et al., 2008; Lam and Teng, 2009) towards the development of constitutive models for simulating stressstrain behaviour. Most of these models were calibrated against their own sets of experimental data. On the other hand, the experimental results available in the literature encompass a wide range of values of the significant variables and can therefore be used for a systematic assessment of the effectiveness of an existing model. In such studies, it has been observed that the response behaviour is dependent on the shape of the core concrete element which has to be confined and also on the specifications of the concrete.

Researchers have observed traditional types of failures that can reduce the performance of CFRP when it is used in retrofitting structures (Esfahani et al., 2007). These failures are often brittle and include the debonding of concrete layers, the delamination of the CFRP, and shear collapse. Brittle debonding has particularly been observed at laminate ends, due to the high concentration of shear stresses at discontinuities, where shear cracks in the concrete are likely to develop (Teng et al., 2003). Thus, it is necessary to study and understand the behaviour of CFRP-strengthened RC members, including failure phenomena. Several researchers have simulated the behaviour of the concrete-CFRP interface using a very fine mesh to simulate an adhesive layer, which is defined as a linear elastic material (Ebead and Marzouk, 2004). However, they have not used any failure criteria for the adhesive layer. Many of the researchers who have studied the behaviour of retrofitted structures have, however, not considered the effect of the interfacial behaviour (Hu et al., 2004; Lundquist et al., 2005).

In the present paper, a nonlinear finite element analysis (FEA) has been carried out to simulate the effect of CFRP confinement on concrete cylindrical specimens. Different material models were used to describe the behaviour of a wrapped concrete specimen. An interface model has been developed using a cohesive bond concept for the concrete-CFRP interface. The interaction between the concrete to the cohesive element and the cohesive element to the CFRP has been accounted for in the modeling. A damage model has been used to simulate the failure of the concrete-CFRP interface. The response behaviour of the wrapped concrete specimen with the proposed interface model has been compared with the behaviour of a perfectly bonded condition. The simulation results have been validated with the available results in the literature. Further, a sensitivity analysis has been carried out to study the confinement effects of the number of layers of CFRP on concrete specimens.

\section{FINITE ELEMENT ANALYSIS}

A nonlinear FEA was performed using the general purpose FEA software ABAQUS (2007) for the simulation of CFRP-confined concrete specimens. The models used to represent the cohesive behaviour reported by Khaligi (2009) have been integrated in the present FEA modelling.

\subsection{Material Models}

\subsubsection{Concrete}

An elastic-plastic model was used to model the behaviour of the concrete. Under uniaxial compression, the stress-strain response follows a linear elastic relationship up to the yield point. This point has been taken as the initial plastic point, and the initial plastic strain has

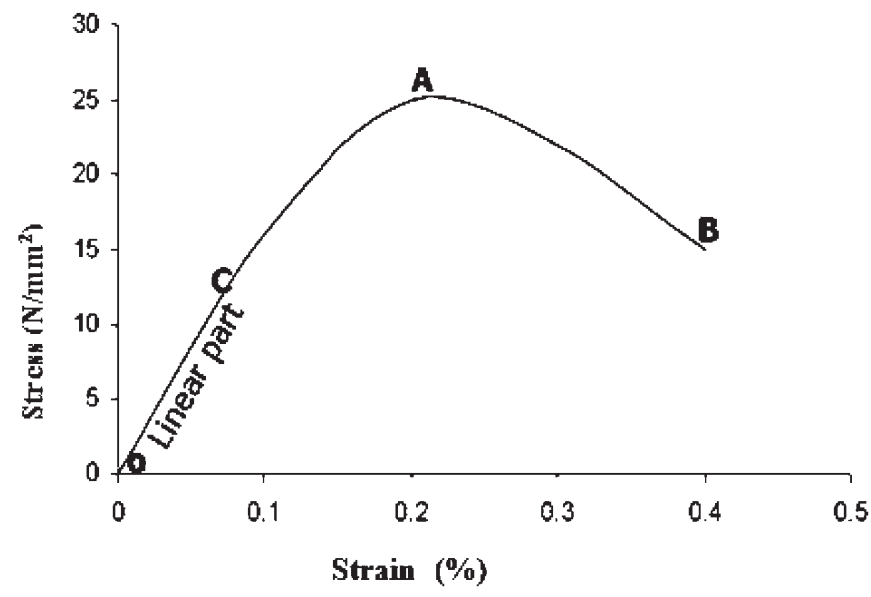

Fig. 1 Stress-strain relationship for concrete under uni-axial compression.

been taken as zero. The stress-strain relationship for M25 grade concrete $(C 25 / 30)$ was used to define the plastic behaviour of the concrete from point $\mathrm{C}$ onwards as shown in Fig. 1. The Poisson's ratio adopted for the concrete was 0.2 .

\subsubsection{CFRP}

The CFRP material was considered to be linear elastic isotropic until failure. Since the composite is unidirectional, it is obvious that the behaviour is essentially orthotropic. When a composite is primarily stressed in the fibre direction, it is probable that the modulus in the fibre direction is the more important parameter. Hence, in the present studies an isotropic model was considered. The elastic modulus in the fibre direction of the unidirectional CFRP material considered for the numerical simulation is $120000 \mathrm{MPa}$ (Ciupala et al., 2003). The value of the Poisson's ratio is 0.15 for the isotropic model.

\subsection{Cohesive Element}

The realistic behaviour of CFRP sheets bonded to concrete with epoxy resin as an adhesive can be modelled by providing the traction versus separation relationship for the cohesive element. The cohesive element is considered as an interface model for such types of problems. In most of the CFRP retrofitted systems, delamination is the governing mode of failure. Prior to such damage, a linear elastic traction-separation law is assumed. The damage process leading to the failure is represented by a progressive degradation of the material stiffness as well. In the present study, the thickness of the epoxy resin layer provided is $0.01 \mathrm{~mm}$. The mechanical values taken for the epoxy resin are the modules of elasticity $\mathrm{E}_{\text {epoxy }}=1067 \mathrm{MPa}$ and the modulus of rigidity $\mathrm{G}_{\text {epoxy }}=746 \mathrm{MPa}$.

\subsection{CFRP-Concrete Interface}

Two different models were used to represent the interface between the concrete and CFRP. In the first model, the interface was modelled as a perfect bond, which assumes no traction-seperation behaviour between the concrete and CFRP. In the second case, the interface was modelled using a cohesive zone model, which would simulate the actual behaviour of the concrete with CFRP confinement. 


\subsubsection{Concrete-Cohesive and CFRP-Cohesive Interaction}

While performing finite element modelling of concrete-confined specimens with different materials, if the two neighboring layers do not have compatible meshes, the top and/or bottom surfaces of the cohesive layer can be tied to the surrounding structures using a tie constraint. Such a situation arises in the case of CFRP confinement because the discretization level in the cohesive layer that is finer differs from the discretization level in the surrounding structures. There is a need to consider two separate types of interaction modelling such as concrete to cohesive interaction and CFRP to cohesive interaction. A pictorial representation of such a situation is shown in Fig. 2, in which the cohesive layer is represented by a finer discretization than the neighboring elements.

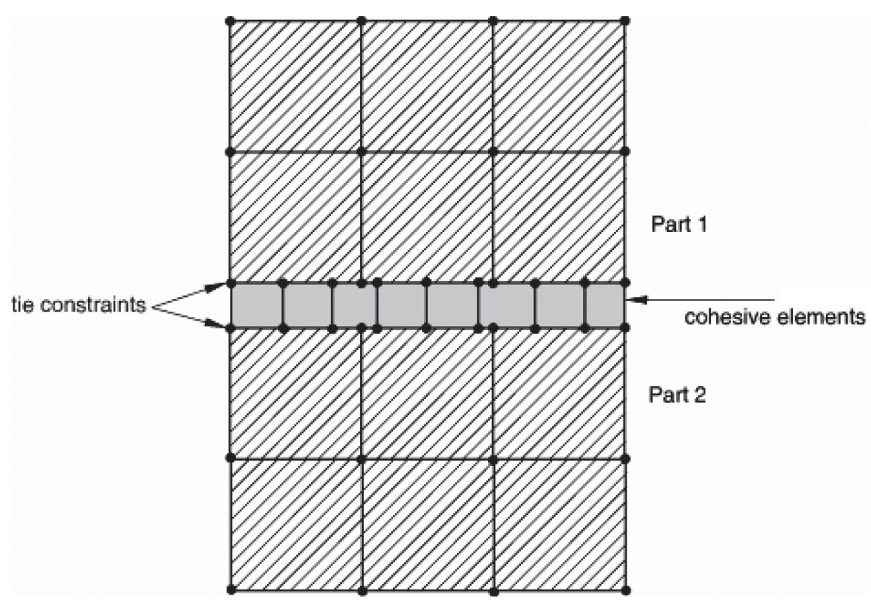

Fig. 2 Mesh interaction with tie constraints.

\subsubsection{Concrete-CFRP Interaction}

As the delamination initiates and progresses between the concrete and CFRP, the cohesive elements completely degrade as a result of the deformation. Subsequently, the elements that are bonded together by the cohesive elements come into contact with each other. Once they are fully delaminated, the cohesive elements will be completely damaged. Hence, simple tangential and normal contact behaviors were selected, and it is assumed that the normal behavior is a hard contact and that the tangential behavior is with a friction coefficient of 0.2 .

\subsection{Traction-Separation Behaviour}

A linear elastic behaviour is assumed for the traction-separation model up to the initiation of delamination. The elasticity is defined in terms of nominal tractions and nominal strains. It is assumed that each traction component depends only on its conjugate nominal strain. The stress-strain relations for uncoupled behavior are given below as:

$$
\left\{\begin{array}{l}
\mathrm{t}_{\mathrm{n}} \\
\mathrm{t}_{\mathrm{s}} \\
\mathrm{t}_{\mathrm{t}}
\end{array}\right\}=\left[\begin{array}{ccc}
\mathrm{K}_{\mathrm{nn}} & & \\
& \mathrm{K}_{\mathrm{ss}} & \\
& & \mathrm{K}_{\mathrm{tt}}
\end{array}\right]\left\{\begin{array}{l}
\varepsilon_{\mathrm{n}} \\
\varepsilon_{\mathrm{s}} \\
\varepsilon_{\mathrm{t}}
\end{array}\right\}
$$

The quantities $t_{n}, t_{s}$, and $t_{t}$ represent the nominal tractions in the normal and the two local shear directions, respectively, and $\mathrm{K}_{\mathrm{nn}}, \mathrm{K}_{\mathrm{ss}}$ and $\mathrm{K}_{\mathrm{tt}}$ represent the stiffness in the normal and the two local shear directions respectively, while the quantities $\varepsilon_{\mathrm{n}}, \varepsilon_{\mathrm{s}}$, and $\varepsilon_{\mathrm{t}}$ represent the corresponding nominal strains.

\subsection{Modeling the Damage to the Interface}

The damage happening to the interface is represented by a failure mechanism as typically shown in Fig. 3. Until the initiation of the damage, the cohesive element is assumed to be linear. A damage initiation and evolution law is used to represent the material damage happening to the cohesive element. The notations $\mathrm{t}^{\mathrm{t}}{ }_{\mathrm{n},} \mathrm{t}_{\mathrm{s},}^{\mathrm{o}}$, and $\mathrm{t}_{\mathrm{t}}^{\mathrm{o}}$ used in Fig. 3 represent the peak values of the nominal stress.

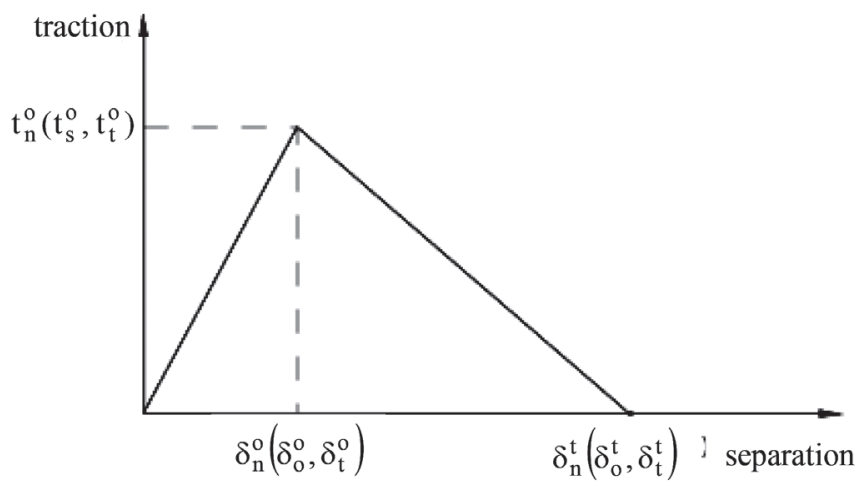

Fig. 3 Typical Traction-Separation Response.

The damage is assumed to be initiated when a quadratic interaction function involving the nominal stress ratios reaches a value of one as given in Eq. (2).

$$
\left\{\frac{\left\langle\mathrm{t}_{\mathrm{n}}\right\rangle}{\mathrm{t}_{\mathrm{n}}^{0}}\right\}^{2}+\left\{\frac{\left\langle\mathrm{t}_{\mathrm{s}}\right\rangle}{\mathrm{t}_{\mathrm{s}}^{0}}\right\}^{2}+\left\{\frac{\left\langle\mathrm{t}_{\mathrm{t}}\right\rangle}{\mathrm{t}_{\mathrm{t}}^{0}}\right\}^{2}=1
$$

Once the damage is initiated, a damage evolution law is used to describe the rate at which the material stiffness is degraded. An energy criteria is considered for the damage evolution in the present study where the fracture energy was used as the input for the damage evolution. In the fracture, a mixed mode behaviour was considered by treating each mode independently along with softening effects, when the material is under tension. The fracture energy is equal to the area under the traction-separation curve (Fig. 4), and an exponential softening behavior is used.

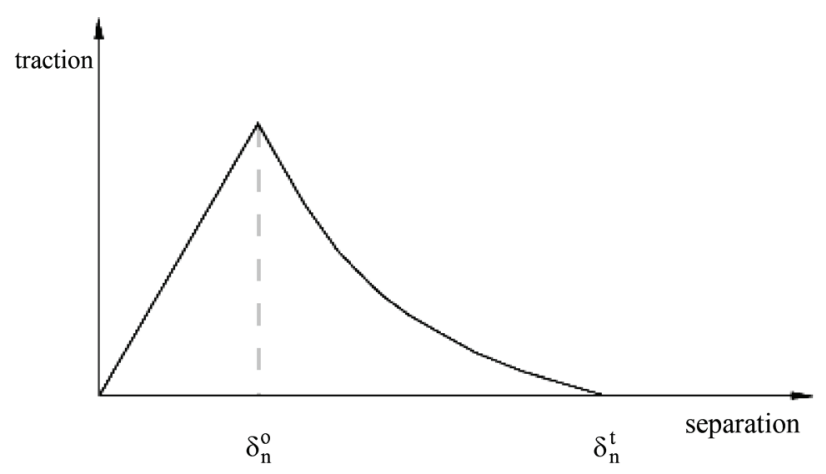

Fig. 4 Exponential Damage Evolution.

Since the mixed mode deformations consist of normal and shear deformations in the cohesive element, the mixed mode definitions based on energy are calculated as 


$$
\mathrm{m}_{1}=\frac{\mathrm{G}_{\mathrm{n}}}{\mathrm{G}_{\mathrm{T}}}, \quad \mathrm{m}_{1}=\frac{\mathrm{G}_{\mathrm{n}}}{\mathrm{G}_{\mathrm{T}}}, \quad \mathrm{m}_{1}=\frac{\mathrm{G}_{\mathrm{n}}}{\mathrm{G}_{\mathrm{T}}},
$$

where, $\mathrm{G}_{\mathrm{n}}, \mathrm{G}_{\mathrm{s}}$ and $\mathrm{G}_{\mathrm{t}}$ are the work done by the tractions and their conjugate relative displacements in the normal, first, and second shear directions, and $\mathrm{G}_{\mathrm{T}}$ is the sum of the normal, first and second shears. It is also useful to consider $G_{s}=G_{s}+G_{t}$ to denote the portion of the total work done by the shear traction and the corresponding relative displacement components. Further, the material properties related to the damage evolution are the functions of $\mathrm{m}_{2}$ and $\mathrm{m}_{3}$. The definitions of the mixed mode based on the traction components are given by

$$
\begin{aligned}
& \phi_{1}=\left(\frac{2}{\pi}\right) \tan ^{-1}\left(\frac{\tau}{\left\langle\mathrm{t}_{\mathrm{n}}\right\rangle}\right), \\
& \phi_{2}=\left(\frac{2}{\pi}\right) \tan ^{-1}\left(\frac{\mathrm{t}_{\mathrm{t}}}{\left\langle\mathrm{t}_{\mathrm{s}}\right\rangle}\right)
\end{aligned}
$$

where $\tau=\sqrt{t_{s}^{2}+t_{t}^{2}}$ is a measure of the effective shear traction. The angular measures used in the above definition (before they are normalized by the factor $2 / \pi$ ) are illustrated in Fig. 5 .

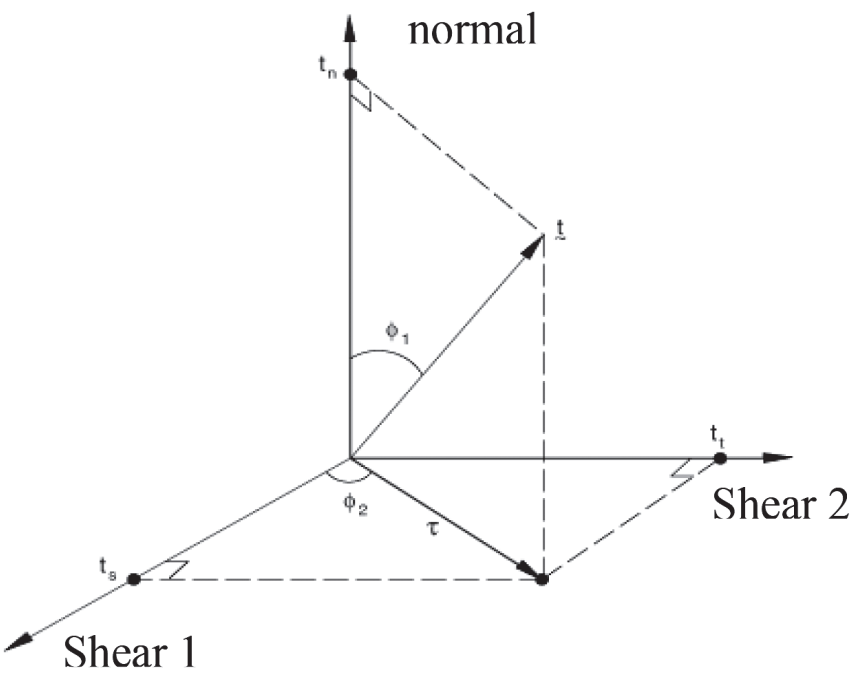

Fig. 5 Angular Measures Based on Traction.

There are two components to the definition of the evolution of the damage. The first component involves specifying either the effective displacement at complete failure, $\delta_{\mathrm{m}}$, relative to the effective displacement at the initiation of the damage, $\delta_{\mathrm{m}}$; or the energy dissipated due to failure, $G_{C}$ (Fig. 6).

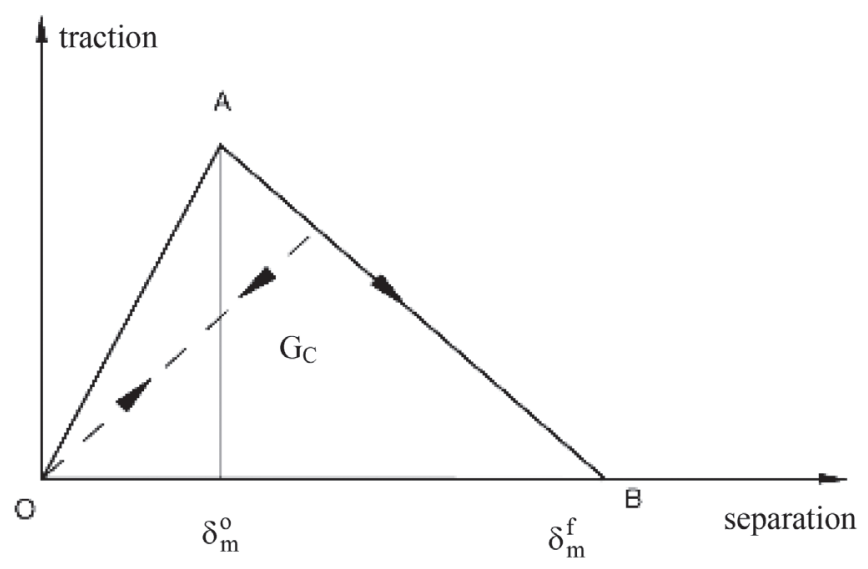

Fig. 6 Linear Damage Evolution.
The dependence of the damage initiation and evolution on the mode mix for a traction-separation response with isotropic shear behavior is shown in Fig. 7. The dependence of the damage evolution data on the mixed mode can be analytically defined as an energy-based definition. In Fig. 7, the traction is presented in the vertical axis, and the magnitudes of the normal and shear separations are presented along the two horizontal axes. The two vertical coordinate planes which are unshaded, represent the response under pure normal and pure shear deformations, respectively. All the intermediate vertical planes represent the damage response under mixed mode conditions, and these maps to the delamination growth.

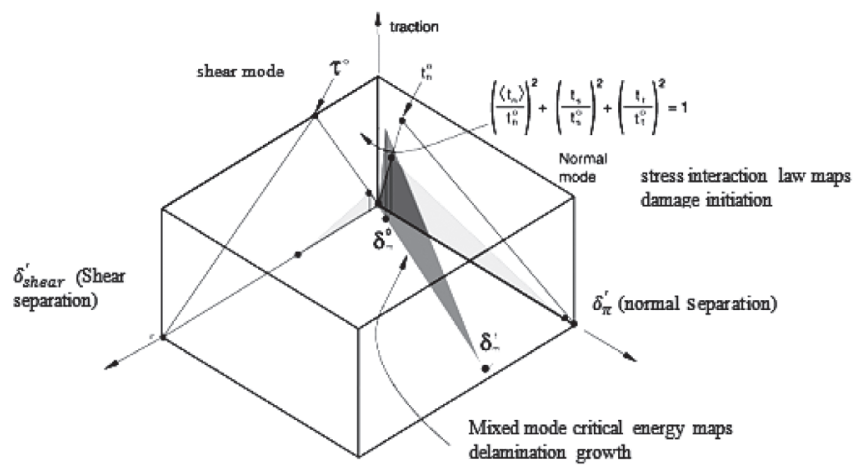

Fig. 7 Mixed-Mode Response in Cohesive Elements.

\section{NUMERICAL INVESTIGATIONS}

Numerical studies were carried out in order to validate the proposed numerical model by conducting a nonlinear FEA. The experimental data reported by Ciupala et al (2003) for a cylindrical specimen of a diameter of $150 \mathrm{~mm}$ and a height of $300 \mathrm{~mm}$ wrapped with CFRP was considered for the numerical simulation. Each CFRP layer is of a $0.117 \mathrm{~mm}$ thickness. The loading was monotonically increased up to failure. It was observed experimentally that the failure of the confined concrete was dominated by the rupture of the jacket and the crushing of the concrete. The experimental results showed that a significant increase in the strength and ductility of concrete can be achieved by one layer of carbon fiber composite jacketing.

For the finite element modelling of both the FRP and concrete parts, a 20-node quadratic solid element (Fig. 8) was selected.

Eight-noded 3-D cohesive elements were used to model the interface layer. The cohesive interface elements were composed of two surfaces separated by a thickness (Fig. 9). The relative motion of the bottom and top parts of the cohesive element measured along the thickness direction represents the opening or closing of the interface. The relative motion of these parts represents the transverse shear behaviour of the cohesive element. To show the effect of the bond model and the behaviour of the CFRP, four combinations of the bond model and CFRP model were analysed. The two cases considered are:

1) a perfect bond with an isotropic CFRP,

2) a cohesive bond model with an isotropic CFRP.

Regarding the boundary conditions, all the nodes in the bottom surface of the cylinder were constrained. The top of the cylinder is allowed to move only in an axial direction (Fig. 10). Fig. 11 shows the finite element (FE) model used in the present study. The nonlinear static analysis was carried out using the Newton-Raphson scheme. 


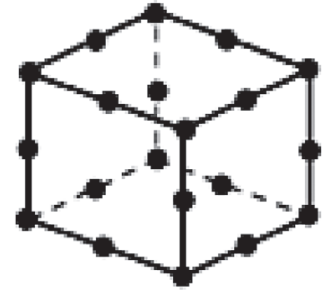

Fig. 8 20-Node Brick, C3D20.

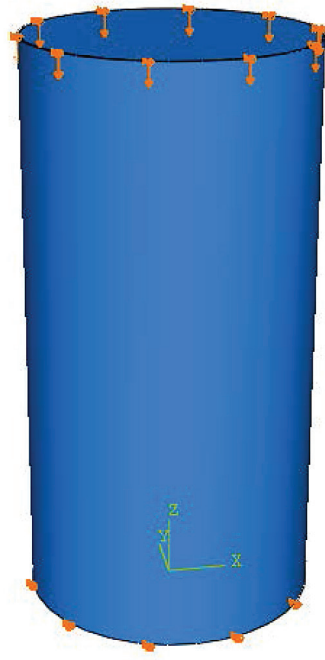

Fig. 10 FE Model with Boundary Conditions.

\subsection{Results and Discussions}

For performing a static nonlinear FEA, two different combinations of models for the concrete and CFRP interfaces using the surface-to-surface approach for a perfect bond and a cohesive model for traction separation were used. The stress-strain curves obtained for the one layer CFRP-wrapped concrete cylinder for both cases are shown in Fig. 12. From Fig. 12, it can be observed that in the linear range, the cohesive model is stiffer compared to the perfect bond model, whereas in the nonlinear range, the cohesive model is flexible.

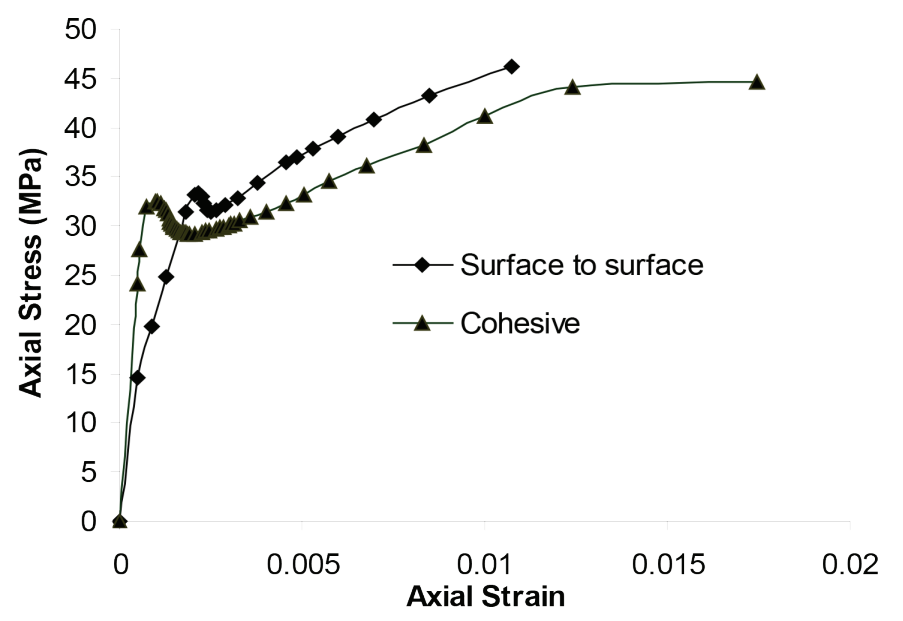

Fig. 12 Axial Stress- Strain Plot for Surface to Surface \& Cohesive Models.

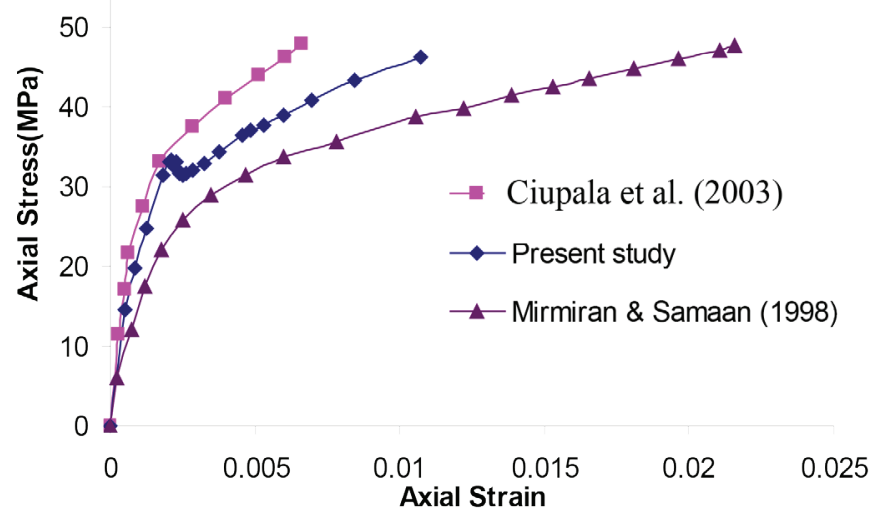

Fig. 13 Axial Stress- Strain Plot for CFRP.

In Fig. 13, the axial stress-strain behaviour of the cohesive model is compared with the corresponding experimental results (Ciupala et al., 2003) and the analytical results (Mirmiran and Samaan, 1998) available in the literature. From Fig. 13, it can be observed that the the present model and experimental behaviour are in close agreement up to an axial stress level of 34MPa. The maximum axial stress is also the same in both cases, whereas the axial strain corresponding to the peak axial stress is $42 \%$ lower in the present model. However, while comparing the present model with one of the analytical models available in the literature, it is observed that the analytical model shows more flexible behaviour than experimental behaviour. More flexibility will overpredict the actual behaviour in terms of the failure mechanism.

The simulation was capable of predicting this behaviour due to the incorporation of the interaction model, the damage criteria, and its evolution during the numerical modelling. Further, the load-deflection curves were obtained for the plain and one-layer CFRP-confined concrete cylinder. The gain in the load-carrying capacity due to the CFRP confinement is shown in Fig. 14. There is about an $80 \%$ increase in the ultimate load. It can also be noted that the ductility of the specimen increases with the confinement.

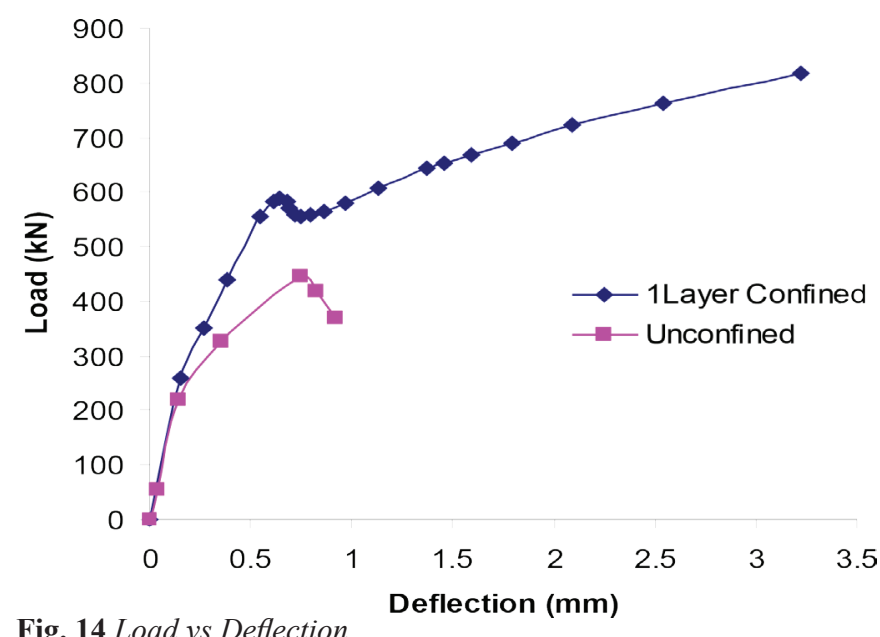

\subsection{Sensitivity Analysis}

A sensitivity analysis was performed for the CFRP with respect to the number of wrapping layers. A FEA was carried out for the concrete specimens wrapped with 1, 2 and 3 layers of CFRP, keeping the compressive strength of the concrete as a constant. Fig. 15 shows the plot of the axial stress-strain behaviour of the CFRP with 1,2 and 3 
layers. From Fig. 15, it can be observed that the axial stress increases with the increase in layers. The stiffness decreases for the 3-layered confinement compared to the 1 and 2-layer confinements. This may be due to the debonding occurring between the layers. Since the rupture strain of CFRP is 0.01 , it can be concluded that there is an optimal number of layers, beyond which the strain becomes unrealistic and the stress-strain response becomes flexible with a higher load-carrying capacity.

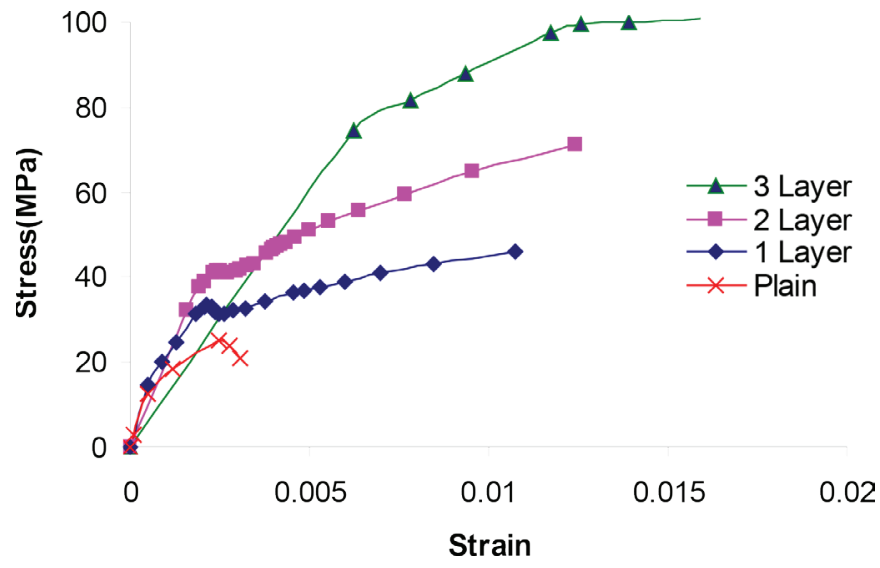

Fig. 15 Axial stress-strain plot for CFRP.

\section{CONCLUSIONS}

A numerical model has been proposed to analyze a concrete specimen wrapped with CFRP using the finite element approach. The material model includes the nonlinear behaviour of concrete in compression and the elastic isotropic behavior of the CFRP. A cohesive model has been employed to consider the interfacial effects between the CFRP and concrete. A damage model has been employed to simulate the failure of the concrete to the CFRP interface. The interaction between the concrete to the cohesive element and the cohesive element to the CFRP has been accounted for by the numerical model. The predictions using the nonlinear FEA showed good agreement with the corresponding experimental results. From the study, it can be observed that the load-carrying capacity increases with the wrapping of CFRP layers. It is observed that the cohesive model is flexible in the nonlinear range compared to the perfect bond model. Further, the proposed model is capable of simulating the rupture failure corresponding to a strain of 0.01 for the CFRP accurately as observed in the experiment. A sensitivity analysis has been carried out, and it has been observed that two layers of the CFRP wrap were found to be the optimum, beyond which the response becomes flexible with a higher load-carrying capacity.

\section{Acknowledgement}

The authors thank Dr. G.S. Palani, Mr. S. Maheswaran and Mr. V. Ramesh Kumar, scientists, for their fruitful discussions during the study. This paper is being published with the kind permission of the Director, CSIR-SERC.

\section{REFERENCES}

Abaqus/CAE 6.7. (2007) User manual, Simulia.

Ciupala, M.A. - Pilakoutas, K. - Taranu, N. (2003) Confinement of Concrete Cylinders with Fibre Reinforced Composite Jackets. Ovidius University Annals Series: Civil Engineering, Vol. 1, No. 5, pp. 133-138.

Colomba, F. - Tobbib, H. - Ferrierb, E. - Hamelin, P. (2008) Seismic retrofit of reinforced concrete short columns by CFRP materials. Composite Structures, Vol. 82, No. 4, pp. 475-487.

Ebead, U. - Marzouk H. (2004) Tension-stiffening model for FRP strengthened RC concrete two-way slab. Materials and Structures, pp. 193-200.

Esfahani, M. - Kianoush, M. - Tajari, A. (2007) Flexural behaviour of reinforced concrete beams strengthened by CFRP sheets. Engineering Structures, Vol. 29, No. 24, pp. 28-44.

Campione, G. (2006) Influence of FRP wrapping techniques on the compressive behavior of concrete prisms. Cement and Concrete Composites, Vol. 28, No. 5, pp. 497-505.

Hu, H.T. - Lin, F.M. - Jan, Y.Y. (2004) Nonlinear finite element analysis of reinforced concrete beams strengthened by fibre-reinforced plastic. Composite Structures, Vol. 63, pp. 271-81.

Khalighi, Y. (2009) A study of bond between fiber reinforced polymer and concrete under quasi-static and impact loading. $\mathrm{PhD}$ Thesis, University of British Columbia.
Lam, L. - Teng, J.G. (2009) Stress-strain model for FRP-confined concrete under cyclic axial compression. Engineering Structures, Vol. 31, No. 2, pp. 308-321.

Lundquist, J. - Nordin, H. - Täljsten, B. - Olafsson T. (2005) $\mathrm{Nu}$ merical analysis of concrete beams strengthened with CFRP $-a$ study of anchorage lengths in FRP in construction. Proceedings of the international symposium of bond behaviour of FRP in structures, pp. 247-54.

Mirmiran, A. - Samaan, M. (1998) Model of concrete confined by fiber. Journal of Structural Engineering. American Society of Civil Engineers, Vol. 124, No. 9, pp. 1025-1031.

Teng, J.G. - Smith, S.T.- Yao, J. - Chen, J.F. (2003) Intermediate crack-introduced debonding in beams and slabs. Construction and Building Materials, Vol. 17, No. 6-7, pp. 447-62.

Toutanji, H. (1999) Stress-strain characteristics of concrete columns externally confined with advanced fiber composite sheets. Aci Materials Journal, Vol. 96, No.3, pp. 397-404.

Xiao, Y. - Wu, H. (2000) Compressive behavior of concrete confined by carbon fiber composite jackets. Journal of Materials in Civil Engineering, Vol. 12, No. 2, pp. 139-146. 